\title{
Suppletive (?) tonal alternations in Munken nouns
}

\author{
Jesse Lovegren
}

March 14, 2012

\section{Phonologically conditioned suppletive allomorphy}

In phonologically conditioned suppletive allomorphy (PCSA) (cf. Carstairs, 1990; Paster, 2006), the selection of suppletive allomorphs depends on the phonological environment. A familiar example comes from Korean, where the nominative suffix has two suppletive allomorphs, /-ka/, and /-i/. The first attahes to vowel-final nouns, the second to consonant-final nouns:

$$
\begin{array}{ll}
\text { pi-ka } & \text { sasil-i } \\
\text { rain-Nom } & \text { truth-NoM } \\
\text { 'rain' } & \text { 'truth' }
\end{array}
$$

In the largest typological study of PCSA to date, Paster (2006) surveyed 137 cases of PCSA in 67 languages. She found that conditioning factors in the observed cases were typically either segmental or prosodic. Only two cases of tonally-conditioned PCSA were discovered, a result she found "puzzling", commenting thus:

There is the possibility that some cases were missed by the survey, but given the efforts to make the survey large and balanced, it seems unlikely that such a significant class of examples could have been systematically neglected. (2006:110-1)

The most obvious interpretation of Paster's results is that tonally conditioned PCSA is in fact extremely rare. Before accepting this interpretation, however, it is important to consider the possibility that a significant class of examples was systematically neglected, though not for want of a large and balanced survey. Since Paster's stated focus was on affixal morphology, it may have been that non-affixal morphological processes were not as carefully scrutinized. Another way that cases of tonal PCSA might have been missed could involve Paster's decision to "... focus on the clearest cases..." (2006:31) of suppletion. The problem of cases of tonal allomorphy which are unclear as to whether they are suppletive is the focus of this paper. I will consider as a case study a set of tonal alternations observed in the Munken dialect of Mungbam.

\footnotetext{
${ }^{0}$ Thanks are due to my Munken consultants: Belta Ngong, Kizita Simpe, Bong Christian, Esther Nungo, Mbelebo William, Pawbe Kelvin; fellow academics: Diana Archangeli, David Fertig, Jeff Good, Kristin Kalinowski, J.P. Koenig, Karin Michelson, Douglas Pulleyblank, Karl Savestani, Adam Sposato, Jay Stallings, Jennifer Wilson, Hiroto Uchihara; funding sources: NSF grant BSC-0853981, University at Buffalo College of Arts and Sciences Humanities Institute
} 


\section{Tonal alternations in Munken nouns: a potential case of tonally- conditioned PCSA}

Munken is one of five varieties of the Mungbam (ISO 693-3 [mij]) language (Bantoid, Cameroon, Good et al., 2011), subject to ongoing fieldwork by the author. Munken contrasts four pitch levels in surface forms. Specification of the number of underlying levels is complicated by two facts: Firstly, the full-range of contrasts is only present in stem-initial syllables of nouns; and secondly, nouns are at least disyllabic, with a mandatory $(C) \mathrm{V}$ noun class prefix, whose tone is in most cases predictable from the stem-initial tone. Minimal sets showing a four-way contrast involving level tones are therefore unavailable. The possible surface tones appearing on stem-initial syllables of nouns are illustated in (2).

(2)

\begin{tabular}{|c|c|c|}
\hline Stem-Initial Tone & Example & Gloss \\
\hline$\overline{\mathrm{L}(\mathrm{ow})}$ & ì-wì & 'cL9-tree hyrax' \\
\hline $\mathrm{M}(\mathrm{id})$ & cì-nsō & 'cL19-needle' \\
\hline $\mathrm{H}($ igh $)$ & ī-kú & 'CL5-filth' \\
\hline S(uperhigh) & í-wí & 'CL10-tree hyraxes' \\
\hline$\widehat{M L}$ & cī-ykwà̀n & 'cL19-lizard' \\
\hline$\widehat{\mathrm{HM}}$ & ā-tsé & 'CL12-chameleon' \\
\hline$\hat{\mathrm{HL}}$ & cì-bûs & 'CL19-cat' \\
\hline$\widehat{L M}$ & ì-tš̌ & 'CL5-cork' \\
\hline
\end{tabular}

Stem-initial $\widehat{\mathrm{ML}}$ and $\mathrm{S}$ tones on nouns in citation form become syncretic when the noun is followed by any L-tone or S-tone possessive pronoun. Nouns with any stem-initial citation tone other than $S$ or ML undergo minimal or no change (examples (3)-(5)).

(3)

ā-kî 'cl12-stone'
ú-gbž 'cL3-rope'
bì-mfēe 'cL 8 -cocoyams'
bò-ndzù 'Cl2-bush cows'
á-tsé 'cL12-chameleon'

ā-kí ma̋ 'my stone'
ú-gbé må 'my rope'
bì-mfē må 'my cocoyams'
bò-ndzù mä 'my bush cows'
á-tsé məz 'my chameleon'

ā-kí bà 'y'all's stone'
ú-gbé bà 'y'all's rope'
bì-mfē bà 'y'all's cocoyams'
bò-ndzù bà 'y'all's bush cows'
á-tsé bà 'y'all's chameleon'

The tone changes, which are not observed elsewhere in the grammar, can be summarized as in (6)-(7):

(6) $\left\{\begin{array}{l}\widehat{\mathrm{ML}} \\ \mathrm{S}\end{array}\right\} \rightarrow \widehat{\mathrm{HM} / \ldots \mathrm{S}}$

$$
\left\{\begin{array}{l}
\widehat{M L} \\
\mathrm{~S}
\end{array}\right\} \rightarrow \mathrm{S} / \mathrm{L}
$$

If any of these alternations are suppletive, then the Munken data would constitute example of tonally-conitioned PCSA, otherwise not reported for an African language. Furthermore, the data represent a possible case of phonologically-conditioned suppletive stem-allomorphy, presenting a possible challenge to Corbett's (2007:22) suggestion that phonological factors do not legitimately condition suppletive stem allomorphy.

\section{What constitutes suppletion in tonal alternations?}

Several criteria for diagnosing whether or not a particular alternation should be considered suppletion can be distinguished in works by different scholars. I consider here four. The first is the condition that alternants should be etymologically unrelated (Rudes, 1980:660). This criterion is 
generally rejected by other commentators (cf. Mel'čuk, 1994: 355; Fertig, 1998: 1065; Veselinova, 2006: 14) who insist on a synchronically valid definition. Two criteria which can be distinguished in the writings of Igor Mel'čuk on the topic are that the alternation be restricted to a single lexical item (1994:378-80), or that the alternation be restricted to a particular morphological environment (1994: 378). While qualititatively similar, the criteria have different outcomes when they are applied to stems as compared to when they are applied to stems. The requirement of lexical idiosyncracy is considerably more exclusive than the requirement of uniqueness of morphological environment when stem allomorphy is considered. For affixal allomorphy, however the two criteria are equivalent, since affixes themselves are the exponents of morphological environments. The fourth criterion, common in generative approaches to morphology (Spencer, 1991:121, etc.), is that alternants not be obviously/plausibly/credibly derivable from a single underlying representation (UR).

When the Munken tone alternations are considered, their status with respect to the etymological criterion is uncertain, but could potentially be resolved with comparative evidence. When the two criteria due to Mel'čuk are taken separately, they lead to unambiguous, but contrary diagnoses. The alternations are restricted to a single morphologically environment, but are not lexically idiosyncratic. In fact, the very possibility of stating that the alternation is phonologically conditioned requires that it apply to all stems of a specified phonological shape. A lexically idiosyncratic phonologically conditioned stem alternation is therefore something which seems undiagnosable on methodological grounds. Evaluating the data in light of the generative criterion is more complicated. The issue is that the UR of two allomorphs is normally arrived at by first assuming that such a form exists, so underlying forms can in principle be set up for allomorphs which may in fact be suppletive. At issue is not the impossibility of setting up UR's, but the plausibility of the mechanisms relating URs to surface forms. as Gussmann, 2000: 500 notes, "What counts as a genuine alternation beyond... uncontroversial cases is largely determined by the power of the phonological model rather than the specific nature of the data." For "clear cases" of suppletion, it is not necessary to set up UR's and derivations, except for amusement (e.g., Comrie, 1978). But for borderline cases, it is necessary to carry out an analysis, so that it can be scrutinized for plausibility. This is the task I take up in the next section.

\section{A generative phonological analysis of the Munken tonal alter- nations}

Regular syntagmatic tonal alternations (besides the alternation in question) are limited in Munken, so arguments for the choice of representation are necessarily based on comparative evidence from other Mungbam varieties, and principles of, symmetry, paradigm congruity, feature economy, overall simplicity of the description, ${ }^{1}$ etc. The first step in the current analysis will be to account for the large number of attested surface tones with a more restricted set of underlying tonal primitives. I consider S(uperhigh) and $\mathrm{M}(\mathrm{id})$ surface tones to be raised and lowered variants of underlying $\mathrm{H}$ (igh) tones, respectively, with the lowering and raising due to the effects of non-segmental L(ow) tones in the UR (see, e.g., Clements and Ford, 1979: 204-5; Stewart, 1981:113-5). Key lowering and raising, the process which generates surface $M$ and $S$ tones is proposed to work as follows: $H$ is lowered when fused with a preceding L (a common downstep environment cross-linguistically), and raised when fused with a following L (cf. Hyman, 1993).

The use of these mechanisms can be supported with comparative evidence involving other dialects of Mungbam. Support for representing $\mathrm{M}$ as $\mathrm{D} \mathrm{H}^{2}$ comes from comparison of Ngun and

\footnotetext{
${ }^{1}$ See, respectively, Trubetzkoy (1939/1969: 59); Fischer-Jørgensen (1949: 221-2); Clements (2003); Halle (1957: 67)
} 
Munken verb forms (8). If the forms in (8) are all represented with underlying tone sequence $/ \mathrm{LLH} /$, then the difference in forms can be shown to be due to a preference for avoiding contour tones in Ngun, and a preference for avoiding unparsed L tones in Munken. ${ }^{3}$

\begin{tabular}{lll}
\hline Munken & Ngun & Gloss \\
\hline wù & wū & 'grind!' \\
fwò & fwō & 'measure!' \\
lè & nō & 'do!' \\
bòy & bōy & 'pray!' \\
\hline
\end{tabular}

\begin{tabular}{|c|c|c|}
\hline Munken & Missong & Gloss \\
\hline ú-gbé & $\overline{u ́}-g b \hat{\imath}$ & 'cL3-rope' \\
\hline ú- & $\hat{\mathrm{u}}-6 \hat{\mathbf{1}}$ & 'cL3-knife' \\
\hline í-6ё & $\hat{1}-6 \hat{\imath}$ & 'CL10-fowls' \\
\hline ú-wêh hैै & ú-gúsò & 'CL3-fire' \\
\hline
\end{tabular}

Support for representation of S as H(L) comes from comparison of Munken and Missong noun forms (9): If the forms in (9) are represented with underlying tone sequence /HHL/, then the difference can be analyzed as a stronger dispreference for tone fusion in Missong, and a stronger dispreference for contour formation in Munken.

Stem-initial surface tones $\mathrm{S}$ and $\widehat{\mathrm{ML}}$ are represented in the UR as /HL/ and /LHL/, respectively, in line with the principle that "... tones which become one another should share features." (Hyman, 1986: 117) Finally, the S-tone possessive pronouns are analyzed as being preceded by a floating Htone associative marker. Doing so considerably simplifies the derivational account, and there is a strong precedent for non-segmental associative morphemes in nearby languages ( $c f$. Tamanji and Ndamsah, 2004: 66-8).

Once the above representational assumptions are made, a phonological account can be made using the Optimality Theory formalism (Prince and Smolensky, 2002) without resorting to any unusual or novel constraint sets. Contraints which are undominated throughout the analysis include a constraint requiring all syllables to be associated with a tone (SPECIFY (Myers, 1997: 861)), one requiring all contour tones to fall on stem-initial syllables (Coincide(Contour, 1st Stem $\sigma$ ) (Zoll, 2003: 236)), one banning unparsed H tones ( ${ }^{*}$ FloAT-H: Bans unparsed H tones (Myers, 1997: 867)), and one banning multiply-associated tones (No-Long-T (Myers, 1997: 876)). ${ }^{4}$ The interacting contraints are:

- GOCP: A generalized form of the OCP which may apply at any do-

Suzuki (1998: 64) main specified by a level of the prosodic hierarchy. In this case the relevant domain is the syllable, so the constraint penalizes identical adjacent elements linked to the same syllable.

- ${ }^{*}$ Rise: Forbids rising contour tones.

- Coincide (ä, $\neg$ Contour): Forbids $S$ tones as members of a contour.

- ${ }^{*}$ Float-L: Forbids unparsed L tones.

- NoContour: Forbids multiply linked TBU's.

- Uniformity-IO(T): Forbids tonal fusion.

Yip (1999: 10)

Zoll (2003: 236)

Myers (1997: 867)

Pulleyblank (1997: 97)

Myers (1997: 871)

In citation forms, and in forms containing an S-tone possessive pronoun, the following ranking holds: $\left\{\operatorname{GOCP}(\sigma),{ }^{*}\right.$ Rise, CoInCIDE $(" a, \neg$ CONTOUR $\left.)\right\} \gg{ }^{*}$ FLOAT-L $\gg$ NoContour In forms with an L-tone possessive pronoun, the relative ranking of ${ }^{\star}$ FLOAT-L and NoConTOUR is inverted, so that NoContour $\gg{ }^{\star}$ FlOAT-L. The implication is that the L-tone possessive pronoun is associated with a dominance cophonology (Inkelas, 1998:139), which explains the prima facie arbitrariness of the alternations.

\footnotetext{
${ }^{2}$ Here (L) indicates a low tone which has fused with an adjacent high tone to effect a key raising/lowering.

${ }^{3}$ OT tableaux for this and other analyses are given in the accompanying supplementary materials.

${ }^{4}$ N.B. No-Long-T is somewhat more general than ${ }^{*}$ SPREAD (McCarthy, 1995: 53), since it does not require tones to be associated in the UR.
} 


\section{Final evaluation}

Though space limitations have prevented me from outlining the generative analysis presented in the preceding section in more detail, hopefully the details are clear enough to give one an idea of its plausibility as a way of relating surface forms to a single UR. If the analysis is to be considered plausible as a synchronic account, then the Munken alternation is not suppletive. If the analysis is implausible, but on the grounds that a better, more plausible analysis is available, then again the alternation is not suppletive. If the analysis is implausible, and a more plausible analysis is not available, then the alternation is suppletive. My own feeling is that the preceding account is not fully plausible, and that the alternation is in fact suppletive: there is available such a wealth of formal devices which have been recently proposed in the phonological literature that it is difficult to exclude even the most unusual alternations from the class of formally representable phonological alternations processes. There is, however, ample room for disagreement on this issue.

The problem presented by ambiguously suppletive alternations is that deciding their status according to the generative criterion is inherently subjective and open to disagreement. Although the genrative criterion is truth-directed (it is assumed that there is a fact of the matter as to whether an alternation is suppletive), the lack of objective criteria for settling unclear cases is particularly acute for tonal interactions, given the abstract character of tonal analyses in generative phonology. This does not necessarily mean that the generative criterion should be abandoned, though. Mel'čuk's criteria, for example, are not troubled by unclear cases, but they are operational rather than truth-directed (they come with no inherent assumption that there is a fact of the matter about the status of an alternation). However, it may be beneficial to attempt to revisit the etymological criterion, which is truth-directed and may turn out to be less prone to subjectivity than the generative criterion.

\section{References}

Geert Booij, Christian Lehmann, and Joachim Mugdan, editors. Morphologie: Ein internationales Handbuch zur Flexion und Wortbildung, volume 1. Walter de Gruyter, Berlin, 2000.

Andrew Carstairs. Phonologically conditioned suppletion. In Wolfgang U Dressler, Hans C Luschützky, Oskar E Pfeiffer, and John R Rennisson, editors, Contemporary morphology, pages 17-23. Mouton de Gruyter, Berlin, 1990.

George N Clements. Feature economy in sound systems. Phonology, 20(3):287-333, 2003.

George N Clements and Kevin C Ford. Kikuyu tone shift and its synchronic consequences. Linguistic Inquiry, 10(2):179-210, 1979.

Bernard Comrie. On the go went alternation: A contribution (?) to the generative phonology of English. In Tom Ernst and Evan Smith, editors, Lingua Pranca, pages 59-63. Indiana University Linguistics Club, Bloomington, 1978.

Greville G Corbett. Canonical typology, suppletion, and possible words. Language, 83(1):8-42, 2007.

David Fertig. Suppletion, natural morphology, and diagrammaticity. Linguistics, 36(6):1065-1091, 1998.

Eli Fischer-Jørgensen. Remarques sur les principes de l'analyse phonémique. In Le cercle linguistique de Copenhague, editor, Recherches structurales 1949, Interventions dans le débat glossématique, publiées à l'occasion du cinquantenaire de M. Louis Hjelmslev, pages 214-234. Nordisk Sprog-og Kulturforlag, Copenhagen, 1949.

Jeff Good, Jesse Lovegren, Patrick Mvee, Carine Nguanguep, Rebecca Voll, and Pierpaolo Dicarlo. The languages of the Lower Fungom region of Cameroon: Grammatical overview. Africana Linguistica, XVII:101-164, 2011.

Edmund Gussmann. Underlying forms. In Booij et al. (2000), pages 499-510.

Morris Halle. In defense of the number two. In Ernst Pulgram, editor, Studies presented to Joshua Whatmough on his sixtieth birthday, pages 65-72. Mouton, The Hague, 1957.

Larry M Hyman. The representation of multiple tone heights. In Koen Bogers, Harry van der Hulst, and Maarten Mous, editors, The phonological representation of suprasegmentals: studies on African languages offered to John M. Stewart on his 60th birthday, pages 109-152. Foris, Dordrecht, 1986. 
Larry M Hyman. Register tones and tonal geometry. In Harry van der Hulst and Keith Snider, editors, The Phonology of Tone: The Representation of Tonal Register, pages 75-108. Mouton de Gruyter, Berlin, 1993.

Sharon Inkelas. The theoretical status of morphologically conditioned phonology: a case study of dominance effects. In Geert Booij and Jaap van Marle, editors, Yearbook of Morphology 1997, pages 121-155. Kluwer Academic Publishers, Dordrecht, 1998.

John McCarthy. Extensions of Faithfulness: Rotuman Revisited. Rutgers Optimality Archive 110, $1995 . \quad$ URL http://roa.rutgers . edu/files/110-0000/110-0000-MCCARTHY-0-0.PDF.

Igor Mel'čuk. Suppletion: Toward a logical analysis of the concept. Studies in Language, 18(2):339-410, 1994.

Scott Myers. OCP effects in Optimality theory. Natural Language and Linguistic Theory, 15(14):847-892, 1997.

Mary Paster. Phonological conditions on affixation. PhD thesis, University of California, Berkeley, 2006.

Alan Prince and Paul Smolensky. Optimality theory: constraint interaction in generative grammar. Rutgers Optimality Archive, 2002. URL roa.rutgers .edu/files/537--0802/537--0802-PRINCE-0--0.PDF.

Douglas Pulleyblank. Optimality theory and features. In Diana Archangeli and D Terence Langendoen, editors, Optimality Theory: An Overview, pages 59-101. Blackwell, Malden, MA, 1997.

Blaire A Rudes. On the nature of verbal suppletion. Linguistics, 18:655-676, 1980.

Andrew Spencer. Morphological Theory: An Introduction to Word Structure in Generative Grammar. Basil Blackwell, Oxford, 1991.

John Massie Stewart. Key lowering (downstep/downglide) in Dschang. Journal of African languages and linguistics, 3(2): $113-138,1981$.

Keiichiro Suzuki. A typological investigation of dissimilation. PhD thesis, The University of Arizona, 1998.

Pius Ngwa Tamanji and Gratiana L Ndamsah. Constituent structure of the associative construction in Grassfields Bantu. Journal of West African Languages, 31(1):65-88, 2004.

Nikolai S Trubetzkoy. Principles of Phonology. University of California Press, Berkeley, 1969.

Ljuba N Veselinova. Suppletion in Verb Paradigms: Bits and pieces of the puzzle. John Benjamins, Amsterdam, 2006.

Moira Yip. Feet, tonal reduction and speech rate at the word and phrase level in Chinese. Rutgers Optimality Archive 159, 1999. URL http://roa.rutgers.edu/files/159-1196/159-1196-YIP-0-0.PDF.

Cheryl Zoll. Optimal tone mapping. Linguistic Inquiry, 34(2):225-268, 2003. 